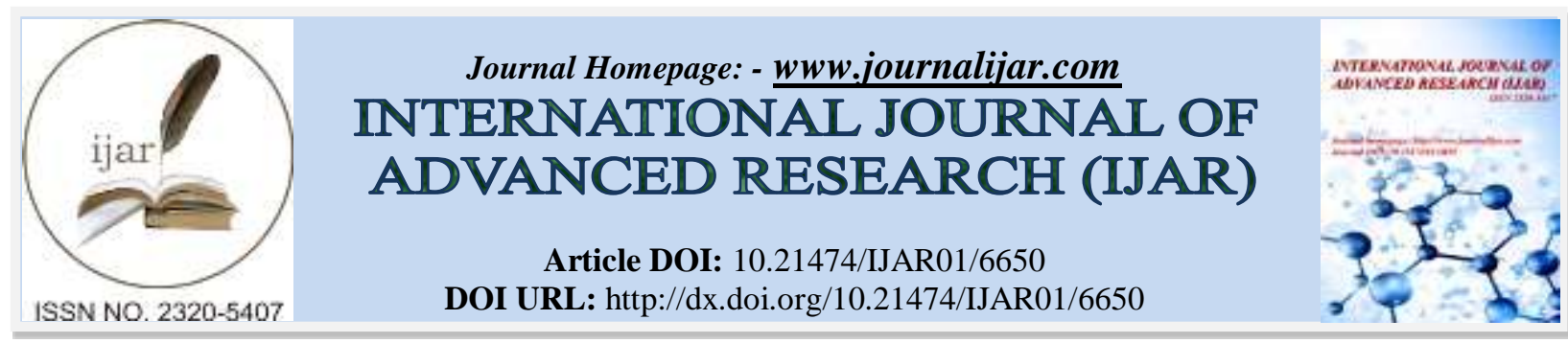

RESEARCH ARTICLE

\title{
INCARCERATED TERM GRAVID UTERUS IN INCISIONAL HERNIA AS A RARE COMPLICATION OF REPEATED CESAREAN SECTIONS.
}

Ebtessam Saad Hassanain ${ }^{1}$ and Adel Awad Elsayed ${ }^{2}$.

1. MBBCH Tanta university Egypt, MD Ain shams university Egypt.

2. MBBCH Mansoura University Egypt, MD Alazhar University Egypt, PHD Alazhar University Egypt.

3. Alahly Hospital Khamis Mushate, Ksa.2006

\section{Manuscript Info}

\section{Manuscript History}

Received: 03 January 2018

Final Accepted: 05 February 2018

Published: March 2018

Keywords:-

Delivery, Gravid, Hernia, Incarcerated, Incisional, Uterus, cesarean section scar.

\section{Abstract}

Incisional hernia of the anterior abdominal wall with recurrent cesarean sections is common but gravid uterus herniating into the sac is rare.

Even rarer is the gravid uterus being incarcerated in the hernia sac. The authors present an interesting obstetric challenge where in a 35years pregnant women un booked with previous 3 cesarean sections before ,presented with 37 weeks pregnancy associated with severely pendulous abdomen and sever tenderness on touch on examination ,it was severely incarcerated uterus with sever dextrorotation in incisional hernia sac.

Copy Right, IJAR, 2018,. All rights reserved.

\section{Introduction:-}

Incarceration of gravid uterus is a rare complication of an incisional hernia but can be diagnosed easily if one is aware.

There are predictable but preventable complications so it is important to add to the information and case reports available in published literature. There are no established management guidelines for such rare conditions; however, reported cases form a good database for taking treatment decisions.

With a rising rate of caesarean deliveries the world over, we may come across this condition more often, especially in the resource poor settings with prevalent malnutrition and high wound infection rates.(2)

\section{Case Details:-}

35year old, para3, previous 3lower segment cesarean section, presented to the antenatal clinic for late booking at 37 weeks gestation, complaining of tenderness on touching her abdomen.

She gave history of previous 3LSCS,last one was one year back and was complicated by sever intrapartum haemorrhage\&massive blood transfusion, delayed healing and post operative wound infection, she got pregnant after 3 months only from last complicated LSCS.

On examination: BMI was $38 \mathrm{kgm} / \mathrm{mm} 2$.

Vitals stable. Abdominal examination reveals severely pendulous abdomen directed towards the thighs, fetal parts felt hardly,FHR $+144 \mathrm{~b} / \mathrm{m}$, scar of lscs was hidden under pendulous abdomen, it was tender, patient felt sever pain and tenderness over abdominal skin. Uterus was incarcerated inside incisional hernia sac. 
Obstetric ultrasound done by radiologist who confirm incarcerated gravid uterus, fetal presentation was complex presentation, placenta was fundal,aminiotic fluid average,cesarean scar was very thin and over stretched, uterus was severely dextrorotated.

Patient HB was 10.5gm, blood group was O+ve, coagulation profile, LFT, RFT, was normal Patient and her husband councelled about her complicated case, she needs urgent admission and emergency cesarean section, informed consent for high risk emergency cesarean section taken by patient and her husband, Consultant surgery contacted by phone to be available in theatre for surgical emergencies and hernia sac repair, mesh was not available at that time, consultant surgery advice separate repair of huge incisional hernia defect with mesh after 2 months of Lscs.

Pediatrician informed to attend LSCS. Blood bank contacted for 4units packed RBCs cross matching.

Patient offered BTL and she agreed and signed with her husband for that.

Patient under spinal anasethia, supine position and left tilt, corrected supported abdominal wall by assistant, midline incision of anterior abdominal wall, there was no muscle layer, left ovary and tube was anterior to the uterus, mild rotation and correction of uterine dextrorotation, incision of upper uterine segment vertically, as there was sever adhesions around lower

Segment, delivery of female baby wt. $3.3 \mathrm{kgm}$

By breech extraction, delivery of placenta and membranes completely, closure of uterine wound in 2 layers.

Bilateral tubal ligation done, Repair of anterior abdominal wall defect by consultant surgeon done, blood loss was about $600 \mathrm{ml}$.Patient stayed 3 days post-operative with abdominal binder, and discharged home $4^{\text {th }}$ post-operative day, follow up visit $7^{\text {th }}$ day, skin stitches removed, wound completely healed, patient continued with abdominal belt ,after 2 months, she was posted for surgical mesh repair .

\section{Discussions:-}

The importance of abdominal hernias in relation to pregnancy is perhaps not sufficiently understood because of their infrequent occurrence. They do, however, occasionally become a real obstetric problem, when complications like herniation of gravid uterus leading to incarceration, strangulation, or burst abdomen develop (1). Herniation of gravid uterus is probably rare because of the fact that by the time the uterus reaches the level of hernial aperture, it is usually too large to enter the hernial sac (3). Careful management is necessary due to potential complications like spontaneous abortion, preterm labor, accidental hemorrhage, intrauterine fetal death, and rupture of lower uterine segment during Labour $(1,3)$.

Herniation of gravid uterus has been reported sporadically as incisional hernia and umbilical hernia of pregnancy (1).

Cesarean section accounted for most of the incisional hernia, accounting for $3.1 \%$ of all cesarean sections. The incidence of incisional hernia was influenced by midline vertical incision, the need for additional operative procedures, more potent and higher quantities of antibiotic administration, postoperative abdominal distension, intraabdominal sepsis, residual intra-abdominal abscess, wound infection, wound dehiscence, postoperative fever, and abdominal incision of previous cesarean section healing with secondary intention $(1,2,3,4$, and 5).

Diagnosis of a gravid uterus in an incisional hernia is made by the history of hernia between pregnancies, presence of an unusual bulge of the abdomen with stretched skin, and easily palpable uterus and fetal parts. Imaging studies like ultrasound and magnetic resonance imaging can assist in diagnosis (2).

Recurrence of hernia in subsequent pregnancies has also been described in 1 patient, in whom 3 consecutive pregnancies were managed successfully with use of abdominal binder but the fourth pregnancy was complicated by incarceration, strangulation, and ulceration of the overlying skin, culminating in cesarean section(2).

The management of these pregnant patients with incisional hernia poses a dilemma as no consensus approach has been described. A conservative approach, including manual reduction of hernia and use of an abdominal binder during the antenatal period and labor, has been applied with varying success (1, 2, and 3). Surgical intervention in the form of antenatal hernial repair in the second and third trimesters has also been undertaken in 2 patients by carrying the pregnancy to term and allowing for normal vaginal delivery. This approach, however, is associated with 
a significant risk of anesthesia and surgical intervention during pregnancy. Moreover, the enlarged uterus itself may hinder optimal herniorrhaphy, and further enlargement with advancing gestation may disrupt the hernia repair. Strangulation at or near term appears to be a genuine indication for early hospitalization and elective cesarean section, possibly combined with hernial repair (3).

The role of abdominal binder during the postoperative period is not known. However, in our experience, we used abdominal binder during the postoperative period in a case of hernia repair with good results. It probably promotes healing as it prevents excessive tension on the site of repair $(4,5)$.

\section{Conclusion and Recommendations:-}

- Avoidance of first cesarean section is mandatory.

- VBAC trials to avoid repeated cesarean section complications.

- Spacing between deliveries to avoid maternal complications.

- Early booking and good ANC to manage high-risk cases.

- Multidisciplinary team is mandatory in managing complicated cases and it, $\mathrm{s}$ follow up.

\section{References:-}

1. Dare FO, Makinde OO, Lawal OO. Gravid uterus in abdominal wall hernia of a Nigerian woman. Int J Obstet Gynecol. 1990;32:377-37

2. Boys CE. Strangulated hernia containing pregnant uterus at term. Am J Obstet Gynecol. 1945; 50:450-452?

3. Banerjee N, Deka D, Sinha A, Prasrad R, Takkar D. Gravid uterus in an incisional hernia. J Obstet Gynaecol Res. 2001; 27:77-79. [PubMed]

4. Malhotra M, Sharma JB, Wadhwa L, Arora R. Successful pregnancy outcome of cesarean section in a case of gravid uterus growing in an incisional hernia of the anterior abdominal wall. Indian J Med Sci. 2003; 57:501503. [PubMed]

5. AL Wadi K,Helewa M,Sabeski ,L.Asymptomatic uterine incarceration at term: a rare complication of pregnancy.J Obstet Gynecol Can 2011:33:729

6. Awojobi OA, Itayemi SO. Abdominal incisional hernia in Ibadan. Trop Doc. 1983;13:112-114

7. Newell SD,Crofts JF,Grant SR.The incarcerated gravid uterus:Complications and lessons learned.Obstet Gynecol 2014:123:423

8. Takami M,Hasegawa $\mathrm{Y}$,Seki $\mathrm{K}$,et al.Spontaneous reduction of an incarcerated gravid uterus in the third trimester.Clin Case Rep 2016:4:605 